\title{
Experiences of Smoking Cessation Focused on Barriers and Facilitators by Husbands with Smoking Tobaccos during Wives Getting Pregnant with Anemia in Urban Community: A Qualitative Research
}

\author{
Napawadee Tungtrongvisolkit1, Bootsakon Seaharattanapatum²* \\ ${ }^{1}$ Community Nursing Department, Faculty of Nursing and Allied Health Sciences, Phetchaburi Rajabhat University, \\ Phetchaburi, Thailand \\ ${ }^{2}$ Public Health Nursing \& Urban Medicine Department, Faculty of Nursing Navamindradhiraj University, Bangkok, Thailand \\ Email: ^bussakorn@nmu.ac.th
}

How to cite this paper: Tungtrongvisolkit, N. and Seaharattanapatum, B. (2021) Experiences of Smoking Cessation Focused on Barriers and Facilitators by Husbands with Smoking Tobaccos during Wives Getting Pregnant with Anemia in Urban Community: A Qualitative Research. Open Access Library Journal, 8: e7460.

https://doi.org/10.4236/oalib.1107460

Received: April 27, 2021

Accepted: May 23, 2021

Published: May 26, 2021

Copyright $\odot 2021$ by author(s) and Open Access Library Inc.

This work is licensed under the Creative Commons Attribution International License (CC BY 4.0).

http://creativecommons.org/licenses/by/4.0/

\begin{abstract}
Background: Smoking induces hypoxia, inflammation, and oxidative stress to the body. Especially, pregnant women with anemia, who are being secondhand smokers. They may lead to adverse health outcomes. Purpose: This phenomenological study aimed to explore the experiences and perceptions of smoking cessation techniques focused on barriers and facilitators by husbands with smoking tobaccos during wives getting pregnant with anemia. Methods: This study was a qualitative study based on Heidegger humanistic phenomenology as a research methodology. Data were collected by using indepth interview, voice record, observation, and field note record from April to August 2019. The saturated sample size of this study was 15 participants. Purposive sampling was used to select willing smokers based on inclusion criteria. The participants were interviewed with the family members until the data saturation was met at home. Data were analyzed using Van Manen's Method. Trustworthiness was established following the criteria of Lincoln and Guba. There were four themes of barriers and facilitators by using Van Manen's four lifeworld existentials: 1) corporeality or lived body; 2) temporality or lived time; 3) spatiality or living space; 4) relationality or lived relation. The study focused on the experiences of smoking cessation techniques, the barriers and facilitators to support quitting tobacco. Results: The findings help to understand the phenomena of tobacco control in husband smokers during wives getting pregnant with anemia. All of the interviewees identified the barriers and facilitators to stop smoking based on the policy at workplace, social
\end{abstract}


support, and multi alternative therapies for smoking cessation. Conclusion: Nurses can develop effective smoking cessation among the husband smokers based on the contexts to promote health for smokers and second-hand smokers in the urban community.

\section{Subject Areas}

Behavior Change, Public Health Nursing

\section{Keywords}

Barriers and Facilitators, Smoking Cessation, Husbands, Qualitative Research

\section{Introduction}

Several studies have shown that smoking induces hypoxia, inflammation, and oxidative stress to the body [1]. Smokers and secondhand smokers are contaminated by 4000 chemicals from tobacco smoke [2]. Moreover, smoking is a public health problem that can lead to stroke, nasal irritation, middle ear disease, respiratory symptoms, impaired lung function [3], lower respiratory illness, lung cancer, coronary heart disease [4], sudden infant death syndrome, and low birth weight [5] [6] [7]. Especially, pregnant women with iron deficiency anemia, who are being second-hand smokers as their husbands maintain to be heavy smoking [8]. Consequently, these pregnant women have maintained continual anemia throughout pregnancy [9]. Although, they are provided iron supplement and iron dietary, while their hematocrit levels are still lower than $33 \%$ or hemoglobin level less than $11.0 \mathrm{gm} / \mathrm{dL}$. Globally, the World Health Organization (2021) reports that second-hand smokers during pregnancy can increase the risk of intrauterine growth restriction, preterm birth, and stillborn [10] [11] [12]. Additionally, 1.2 million people every year are killed by tobacco products all over the world. In Thailand, more than 70,000 Thais die from smoking-related non-communicable diseases. Smoking can be harmful to pregnant women and fetuses due to husbands smoke during wives getting pregnant [13] [14]. Strong evidences showed that the relationshipof smoking could reduce hemoglobin levels or anemia in pregnant women [15] [16]. Additionally, the odds ratios of anemia during pregnancy were adjusted for maternal age, educational level, socioeconomic status, type of residence, lower body mass index, parity, vegetarian, and hemodilution [17]. Previous study revealed that secondhand smoking in pregnant women was associated with anemia [7].

In Thailand, all pregnant women with IDA are provided knowledge about adequate dietary intakes and adherence to iron supplement at antenatal care clinic, while there is the limitation of smoking cessation or brief advice to quit tobacco for husbands, who smoke during their wives getting pregnancy [8]. Previous studies revealed that pregnant women with secondhand smokers were continually anemia throughout pregnancy because their husbands maintained daily heavy 
tobacco smoking at home [9].

Congruence with the previous study revealed that tobacco smoking influenced hemoglobin levels in pregnant women [10] [11] [12]. This study used phenomenological research method to understand the experiences and perceptions of smoking cessation focused on barriers and facilitators by smoking husbands of pregnant women with anemia in the urban community.

\section{Aims and Objectives}

This phenomenological study aimed to explore the experiences and perceptions of smoking cessation techniques focused on barriers and facilitators by smoking husbands of pregnant women with anemia. This understanding would be useful for nurses to develop the guideline for helping smoking husbands and pregnant women with anemia and secondhand smokers in smoking cessation at antenatal care clinic and continually home visit to encourage the smokers to quit tobacco based on their context.

\section{Methods}

This study was a qualitative study based on phenomenology as research methodology [18]. Thus, the researcher would understand more about human experiences, which influenced their perceptions of experience and perception in each interviewee until the data saturation.

\subsection{Participants}

Convenience sampling method was used to interview smokers, who were the husbands of pregnant women with anemia. The participants and wives were visiting at antenatal care clinic at the university hospital, while the lead author could approach the participants after the register nurses provided them with the essential information and also had willing to participate with this study. The participants were called as interviewees that were recruited from antenatal care clinic of the university hospital in Bangkok, Thailand. However, all interviewees were interviewed later at home based on their available appointments. Moreover, they were interviewed until the data saturation principle from April to September 2019. The inclusion criteria included 1) husbands who had experiences with smoking cessation, 2) aged more than 20 years old, 3) wives getting pregnancy with anemia at gestational age 20 weeks, and 4) visiting antenatal care clinic with their wives.

\subsection{Procedures}

All interviewees had a face-to-face semi-structured interview, which was conducted on the date of appointment in each interviewee at home. This study applied the qualitative interviews using open-ended questions, which were questions that the lead author posed but did not provide answer option for Open-ended questions are more demanding of participants than closed-ended questions. There- 
fore, the participants would come up with their own words, phrases, or sentences to respond. The interviewees were performed face to face by the lead author in appropriate place. Additionally, Audio-recorded, in-depth semi-structured interviews provided an increasingly fluid interview, enabling the research to engage with the interviewee in a phenomenological conversation and focused the interviewees perceived as important. Time average of the interview was approximately 30 minutes, ranging from 25 minutes to 35 minutes. The saturated interviewees were about 15 participants. Before the interview, the lead author and all interviewees had been following the guideline of COVID-19 prevention: wearing mask, face-shield, regarding social distancing from each interviewee about 2 arm lengths, temperature measurement, and hand washing gel with $70 \%$ alcohol. The lead author would introduce the purpose and significance of the study to the interviewees and obtained them to complete the consent on the recordings. In order to protect the privacy of interviewees, all researcher contents were anonymous and the participants' names were numbered instead.

\subsection{Data Collection}

Data were collected by using in-depth interview, voice record, observation, and field note record from April to August, 2019. This stage belongs to the epidemic period of new coronavirus. Therefore, the lead author conducted the research based on the guideline of COVID-19 prevention throughout the interviewing. Purposive sampling was used to select willing smokers based on inclusion criteria until data saturation as 15 participants. The interviewees were interviewed with the family members until the data saturation was met at home. Interviewing skills were required, such as active listening and asking open-ended questions without hidden presumption. During the interview, the author tried not to interrupt the interviewees and meanwhile confirmed their opinions in time.

\subsection{Data Analysis}

The data collection and analysis were carried out simultaneously. After each interview, two researchers transformed the interview recordings into texts within 24 hours, and then analyzed the data by using Van Manen's Method [18]. Trustworthiness was established following the criteria of Lincoln and Guba. There were Van Manen's four lifeworld existentials: 1) corporeality or lived body; 2) temporality or lived time; 3 ) spatiality or lived space; 4) relationality or lived relation. The study focused on the experiences of smoking cessation techniques, the barriers and facilitators to support quitting tobacco. This study used six procedures of Van Manen includes summarizing and refining the common parts of the data, and then two researchers analyzed, reviewed, and corrected the research data to ensure the authenticity and objectivity of results.

\subsection{Trustworthiness, Credibility and Reflexivity}

Trustworthiness and credibility were achieved by transcribing all audio-recordings 
and repeatedly read the transcripts. The first interview probed further into the experiences, verified previously established knowledge and increased the credibility and faithfulness to the interviewees' accounts. The honesty was an important value to ensure respect towards both the individuals and their accounts, while ensuring the genuineness of the inferred interpretations. Furthermore, the study the researcher abided to the four principles put forward by the criteria of Lincoln and Guba;

1) Credibility of a study is determined when coresearchers or researchers are confronted with the experience, they can recognize it. Lincoln and Guba (1985) suggested a number of techniques to address credibility including activities such as prolong engagement, persistent observation, data collection triangulation, and researcher triangulation [19].

2) Transferability refers to the generalizability of inquiry. In qualitative research, this concerns only to case-to-case transfer.

3) Dependability, the researchers can ensure the research process is logical, traceable, and clearly documented. When readers are able to examine the research process, they are better able to judge the dependability of the research.

4) Confirmability is concerned with establishing that the researcher's interpretations and findings are clearly derived from the data, requiring the researcher to demonstrate how conclusions and interpretations have been reached.

These were considered to improve the quality of qualitative research and ensure a neutral and consistent interpretation of data, while respecting the participants and their experiences. A reflective diary was kept throughout the study to keep track of all the decisions taken, particularly the feelings experienced during the interviews.

\subsection{Ethical Issues}

The Ethical approval was obtained from Institutional Review Board of the university's hospital (COA No.126/2019). The personal privacy may be involved in the study, so researcher adhered to the following rules when dealing with ethical issues: the purpose of the project was introduced by the researchers; recording could not be performed until the consent of the interviewees were obtained; the interviewees had the right to quit without prejudice consequences; and gratitude was showed to interviewees.

\section{Results}

\subsection{Participants}

The fifteen participants were included in this study. Ages of all participants were between 25 and 45 years, an average age of $34.33 \pm 5.21$ years old. The family incomes were between 15,000 Baht to 36,000 Baht, the average of family income approximately 26,200 Baht ( $\mathrm{SD}=6760.71)$. Most of participants were Bachelor's degree (53.3\%), High school (26.7\%), and Master's degree (20.0\%). Previous daily smoking tobaccos were between 10 to 20 cigarettes, an average of previous 
smoking about 16.87 cigarettes $(\mathrm{SD}=3.56)$. For current daily smoking tobaccos were between 0 to 20 cigarettes, an average of current smoking about 8.67 (SD = 6.01). The participants had experiences with several smoking cessation techniques; $26.7 \%$ using alternative therapy, $20.0 \%$ quitting cold turkey, behavioral therapies, telephone counseling, and mixed techniques (Table 1 and Table 2).

\subsection{Themes}

The Data were analyzed using Van Manen's Method based on the four lived worlds including: 1) corporeality or lived body; 2) temporality or lived time; 3 ) spatiality or lived space; 4) relationality or lived relation. For corporeality or lived body meant physiological perception that covered the body and mind of the smokers, who had experiences of smoking cessation. Consequently, the five themes were based on the Van Manen's four lived worlds: a) experiences of smoking cessation techniques; b) effects of smoking on health of family members; c) benefits of smoking cessation; d) perception of barriers of smoking cessation; e) perception of facilitators to support smoking cessation.

\subsubsection{Experiences of Smoking Cessation Techniques}

Most interviewees said that they had a wide variety of experiences with smoking cessation techniques. However, all of them preferred to use nonpharmacologic therapies including: 1) alternative therapies; 2) quitting cold turkey; 3) behavioral

Table 1. Participant characteristics $(n=15)$.

\begin{tabular}{|c|c|c|}
\hline Characteristics & Mean (SD) & Number (\%) \\
\hline \multicolumn{3}{|l|}{ Age } \\
\hline \multicolumn{3}{|c|}{$($ Minimum $=25$ years old, Maximum $=45$ years old $)$ Mean $=34.33(S D=5.21)$} \\
\hline \multicolumn{3}{|l|}{ Family incomes } \\
\hline \multicolumn{3}{|c|}{$($ Minimum $=15,000$ Bath, Maximum $=36,000$ Bath $)$ Mean $=26,200(S D=6760.71)$} \\
\hline \multicolumn{3}{|l|}{ Educational levels } \\
\hline High school & & $4(26.7)$ \\
\hline Bachelor's degree & & $8(53.3)$ \\
\hline Master's degree & & $3(20.0)$ \\
\hline \multicolumn{3}{|l|}{ Previous daily smoking tobaccos } \\
\hline \multicolumn{3}{|c|}{$($ Minimum $=10$ cigarettes, Maximum $=20$ cigarettes $)$ Mean $=16.87(\mathrm{SD}=3.56)$} \\
\hline \multicolumn{3}{|l|}{ current daily smoking tobaccos } \\
\hline \multicolumn{3}{|c|}{$($ Minimum $=0$ cigarettes, Maximum $=20$ cigarettes $)$ Mean $=8.67(S D=6.01)$} \\
\hline \multicolumn{3}{|l|}{ Smoking Cessation Techniques } \\
\hline Alternative therapy & & $4(26.7)$ \\
\hline Quitting cold turkey & & $3(20.0)$ \\
\hline Behavioral therapies & & $2(13.3)$ \\
\hline Telephone counseling & & $3(20.0)$ \\
\hline Mixed techniques & & $3(20.0)$ \\
\hline
\end{tabular}


Table 2. Demographic characteristics of interviewees $(n=15)$.

\begin{tabular}{cccccc}
\hline Number & $\begin{array}{c}\text { Age } \\
\text { (years) }\end{array}$ & $\begin{array}{c}\text { The Highest } \\
\text { Education }\end{array}$ & $\begin{array}{c}\text { Previous } \\
\text { Number of } \\
\text { Cigarettes } \\
\text { smoked } \\
\text { daily }\end{array}$ & $\begin{array}{c}\text { Current } \\
\text { Number of } \\
\text { Cigarettes } \\
\text { smoked } \\
\text { daily }\end{array}$ & $\begin{array}{c}\text { Smoking } \\
\text { cessation } \\
\text { techniques }\end{array}$ \\
\hline P1 & 45 & Master's degree & 12 & 4 & 1 \\
P2 & 32 & Bachelor's degree & 18 & 12 & 1 \\
P3 & 34 & Master's degree & 16 & 10 & 1 \\
P4 & 35 & Bachelor's degree & 20 & 11 & 1 \\
P5 & 32 & Bachelor's degree & 18 & 17 & 2 \\
P6 & 30 & High school & 20 & 20 & 2 \\
P7 & 31 & Bachelor's degree & 18 & 18 & 2 \\
P8 & 36 & High school & 20 & 6 & 3 \\
P9 & 27 & Bachelor's degree & 12 & 5 & 3 \\
P10 & 25 & Bachelor's degree & 10 & 4 & 4 \\
P11 & 34 & Master's degree & 12 & 6 & 4 \\
P12 & 40 & High school & 20 & 10 & 4 \\
P13 & 38 & High school & 18 & 0 & 5 \\
P14 & 36 & Bachelor's degree & 20 & 4 & 5 \\
P15 & 40 & Bachelor's degree & 19 & 3 & 5 \\
\hline
\end{tabular}

Remark: alternative therapies (1), quitting cold turkey (2), behavioral therapies (3), telephone counseling (4), and mixed techniques (alternative therapists plus behavioral therapists and telephone counseling) (5).

Therapies; 4) telephone counseling; 5) mixed techniques (alternative therapists plus behavioral therapists and telephone counseling). According to this study, we would describe into the five themes based on Van Manen's four lived worlds including: P1 "I used the famous traditional Chinese medicine as acupressure for smoking cessation in private clinic due to it could release my tension and also did the meditation before my bed times"; P2 "My wife bought some Vernonia cinerea tea for me. She said that it could help me to quit tobaccos during the day of my working, then I must pick up the two bottles of some Vernonia cinerea tea for drinking after my meals"; P3 "I used Thai herb such as some slight lemons for chewing, when I wanted to smoke cigarette during the day"; P4 "I used Thai herb such as slight lemons for chewing, when I wanted to smoke cigarette during the day"; P5 "I had tried to stop smoking by myself without any medicine for several times, but it was difficult to do when I met all friends, who were smoking in my work place. Then, I felt that I wanted continually to start cigarette smoking again. Quitting was so difficult for me. I knew that only myself could not succeed. Anyway, I would try to find the appropriate technique to stop tobaccos for me"; P8 "I received the suggestion from an occupational health nurse at my work place to join with a smoking cessation program. The occupational health nurse provided me with the knowledge of benefits of smoking cessation for me and my smoking colleagues and motivated me to stop tobacco smoking. It was 
effective way for me due to I could meet the occupational health nurse, who could monitor and be coaching me to maintain my smoking cessation continually at work place"; P9 "I felt that I was not alone to stop smoking due to I received the self help group at work place to set the special group for all smokers by opening the opportunity of sharing experiences with other friends, who could stop smoking based on behavioral therapy by sharing direct experience. I followed the guidelines of behavioral therapy from the physician and others friends, who were successful in smoking cessation"; P10 "I would call the Thailand National Quitline Center (The Quitline 1600) for three months. I had more confident to do smoking cessation by consulting the expert from 1600 that she kept calling me and encourage me based on my available time"; P13 "I preferred to apply several ways for smoking cessation at home and work place. For example, occupational health nurse invited me to participate with the health promotion project in my work place. She provided all of tobacco education and also provided the smoker, who could succeed in quitting tobacco to be my coaching and challenge me to stop smoking with a group of current smoking friends. Moreover, she referred me to the call the Thailand National Quitline Center (The Quitline 1600) for three six months before my wife got pregnant pregnancy. I could reduce my daily tobacco smoking from 18 cigarettes to 3 cigarettes. I could do it for six months before my wife got pregnant".

\subsubsection{Effects of Smoking on Health of Family Members}

There were several opinions about smoking effects on health of family members including: 1) the effects of smoking directly to health of only smokers; 2) the effects of smoking directly to health of both smokers and family members; 3) the effects of smoking non-related on health of family members. This could be divided into the three themes. According to the first theme was about the effects of smoking directly to health of only smokers; P8 "I thought that smoking were effects only my health due to I was not smoking inside of my house"; P9 "I smoked in bath room everymorning, and turned on ventilation fan after smoking"; P10 "after I smoked, then I took a shower, so my family members would not contaminate with tobacco smoking"; P12 "I smoke at balcony around the house and this area was quite well air ventilated"; P13 "I could not hear any complaint from all of my family members about my smoking how it was effects on their health. But I knew that it only affects my health". For the second theme was about the effects of smoking directly to health of both smokers and family members; P1 "I had the problems with irritation after smoking and my wife getting pregnancy, so I knew that tobacco smoke could be harmful for my wife and little baby"; P3 "I were warning from occupational health nurse at my work place to quit tobacco due to I had hyperlipidemia based on my annual health checkup. It could increase the risk of stroke. Moreover, I could reduce tobacco smoking for avoiding the toxic of tobacco on my parents, who were elderly with diabetes mellitus and hypertension"; P11 "I thought that smoking would be effects on not only my health, but also would be effects on my family members". The third theme was 
about the effects of smoking non-related on health of family members; P2 "I smoked many years however, I was still healthier and my family members were normal. I thought that smoking was not related to others anymore"; and P4 "I was normal and others around me were not suffering from tobacco smoke".

\subsubsection{Benefits of Smoking Cessation}

All of interviewees knew about the benefits of smoking cessation. However, some of them preferred to smoke tobacco continually. Therefore, the interviewees had several perceptions about benefits of smoking cessation that covered the five holistic dimensions including physical, emotional, social, spiritual, and mental health. The physical dimension included; P6 "I knew that quitting tobacco was good for health and made my tongue perceives the taste of food better". The emotional dimension included; P4 "Smoking cigarettes made me increase my self-esteem due to the fact that I could quit tobacco for my little baby". The social dimension included; P7 "Stop smoking tobacco could be saving my money"; P10 "I believed that it could help good atmosphere and not to produce PM.2.5"; and P13 "My boss said that I would be a role model of smoking cessation for others in my work place". The spiritual and mental health dimension included; P1 "I believed that smoking cessation was the best way to maintain the five precepts of Buddhist due to I am always doing meditation before my bed time"; P13 "I felt good that I did it for my wife and little baby due to God would help my baby strong and wellness".

\subsubsection{Perception of Barriers of Smoking Cessation}

There were different barriers of smoking cessation in each participant. For example, tobacco used for stress management; P7 "I believed that smoking was good for my brain... I was alert and felt better after smoking... I wanted to use tobacco for releasing my tension". It was the habit of smoking; P6 "I felt very difficult to quit tobacco... Because I could not eliminate it in the morning when I try to stop smoking tobacco". It was lack of social support to quit smoking; P7 "I thought that it was difficult to find a smoking cessation center in my community due to the fact that Ilive outside the urban area... It was very far from the hospital... I had no seen any type of smoking service that was fixed with my life style". It was lack of motivation; P6 "There is nothing special for me... I did not want to stop my daily smoking"; P11 "I would like to continue smoking... I could not stop smoking... However, I will stop when I meet my appropriate time". It was lack of knowledge or misunderstanding; P6 "I try to smoke outside or smoke in the toilet to protect my wife and little baby"; and P7 "I believed that my smoking did not have negative effects on my baby". It was high prevalence and convenient acceptability for smoking tobacco in community or work place; P4 "I could find tobacco at workplace from my friends, who were smoking with me during the day of working"; P7 "It was easier to find tobacco from my community... It felt more convenient to buy tobacco, whatever I wanted to smoke; P12 "I could not quit smoking due to I wanted to participate with friends". The five barriers of smoking cessation were found from this study; 1) stress man- 
agement, 2) the habit of smoking, 3) lackof social support to quit tobacco, 4) lack of motivation, 5) lack of knowledge or misunderstanding, and 6) high prevalence and convenient acceptability for tobacco smoking in community or work place.

\subsubsection{Perception of Facilitators to Support Smoking Cessation}

The three facilitators smoking cessation were found from this study: 1) family members including; P1 "I would say that my wife encouraged me to stop smoking"; P13 "My daughter asked me how she could help daddy to stop smoking... I wanted my father to be good health"; P15 "My mother was diagnosed with Diabetes Mellitus and she was staying with me and my wife... So, my mother encouraged me to reduce tobacco smoking until I will stop smoking for all of my family members"; 2) peer groups including; P3 "My friends, who could be able to quit smoking.... They shared with me how to stop smoking.... Yes, they were the best coaching for smoking cessation"; and 3) smoking cessation service including; P9 "My work place had offered smoking cessation by occupational health nurse.... All colleagues were invited to participate with this project at work place... Yes, it was very challenging us to be the winner for smoking cessation as a team work to encourage each other continually".

\section{Discussion}

This study revealed that smoking husbands of pregnant women with anemia had varieties of experiences with smoking cessation. Most participants could be able to reduce their daily tobacco smoking by using 1) alternative therapies, 2) quitting cold turkey, 3) behavioral therapies, 4) telephone counseling, and 5) mixed techniques (alternative therapists plus behavioral therapists and telephone counseling). The finding from this study found that the participants, who had perceived benefits, perceived barriers, and social support of smoking cessation. Consequently, they had good effort overcoming their barriers of quitting tobacco. While, the husbands with smoking tobacco, who had severity of nicotine dependence as habitual smoking behavior, lack of knowledge, and misunderstanding about the tobacco smoking toxins on adverse health effects for smokers and others. Therefore, motivational intervention or tailor intervention based on smokers' context must be concerned to develop the effective smoking cessation intervention among the smoking husbands during their wives getting pregnant. This could reduce negative health outcomes of pregnant women and prevent adverse birth outcomes. Additionally, establishing smoking husbands' views on smoking cessation techniques without medical therapy focused on barriers and facilitators of smoking cessation based on Van Manen's four life world existentials: 1) corporeality or lived body, 2) temporality or lived time, 3) spatiality or lived space, and 4) relationality or lived relation.

\section{Limitation and Future Research}

There were some limitations to this study. Smoking in pregnancy is a sensitive 
and often stigmatized topic and, as such, the smoking husbands tended to be reluctant to fully disclose their smoking behaviors. Especially, as there was increasing pressure on smokers to quit both from health care providers and society in general. It was possible that the responses given may not have been a true reflection of smoking patterns for reasons such as fear of being judged negatively or being put under further pressure to stop.

Future research, gaining deeper insight into the reasons, why some smoking husbands could not be able to stop smoking and how they would get to access the smoking cessation counseling services as soon as possible. Moreover, the communication of peer groups, who could be the best coaching for sharing and encouraging the current smokers to quit smoking.

\section{Conclusion}

It can be concluded from this study that, despite the fact that smokers, who had wives getting pregnant with anemia. Then, some of them could stop smoking as they had good effort or motivation from being good health and fetal development and growth. However, the participants, who were insufficient knowledge of smoking cessation and low motivation, could not overcome the barriers of smoking cessation. The finding from this study revealed that all of the participants used including 1) alternative therapies, 2) quitting cold turkey, 3) behavioral therapies, 4) telephone counseling, and 5) mixed techniques (alternative therapists plus behavioral therapists and telephone counseling). This study could help to understand the barriers and facilitators of smoking cessation among the smoking husbands of pregnant women with anemia. Moreover, the sociological implications of this study revealed that the participants, who had light tobacco use or smoking less than ten cigarettes per day, were having more perceived benefits of smoking cessation and also had good social support from family members. Thus, they had a good opportunity to visit antenatal care clinics and participated to take care of their wives, who were getting pregnant. This activity could help them to meet health care providers, who had recommended all smokers to stop smoking tobacco as much as they could for improving maternal health outcomes and preventing adverse birth outcomes among pregnant women with anemia. Moreover, the participants, who could maintain to quit tobacco, had acceptability from their workplace due to they would be the role model of smoking cessation to other colleges, who could not stop smoking tobacco at workplace. The important finding from this study was the most participants, who could succeed in smoking cessation during wives getting pregnant. They had strong motivation to quit tobacco due to they were encouraged by their family members and health care providers to be concerned about how to overcome the barriers of smoking cessation and discovered the appropriate facilitators to help them be successful in smoking cessation. Thus, nurses can develop the tailored intervention of smoking cessation as the proactive motivation intervention to help smokers and family members to be safe. Furthermore, smoking tobacco can decrease human 
immunization and damage the respiratory organs for smokers and secondhand smokers. Therefore, smoking cessation can reduce the risk factor of COVID-19 for all aged groups.

\section{Acknowledgements}

We would be thankful to all the participants, who accepted to share their experiences with us. The staff assisted in the recruitment of participants and development of the study. Additionally, the research supervisor provided valuable suggestions and recommendations.

\section{Conflicts of Interest}

All authors declare that they have no conflicts of interest.

\section{Data Availability}

All data are available on request from the corresponding author.

\section{References}

[1] Perone, A.K., Dunkle, R.E., Feld, S., Shen, H.-W., Kim, M.H. and Pace, G.T. (2019) Depressive Symptoms among Former Spousal Caregivers: Comparing Stressors, Resources, and Circumstances of Caregiving Cessation among Older Husbands and Wives. Journal of Gerontological Social Work, 62, 682-700. https://doi.org/10.1080/01634372.2019.1647906

[2] Chen, J., Li, X. and Fang, P. (2020) Influence of Family Resources on Secondhand Smoking in Pregnant Women: A Cross-Sectional Study in the Border and Minority Urban Areas of Northwest China. BMC Pregnancy \& Childbirth, 20, Article No. 642. https://doi.org/10.1186/s12884-020-03251-w

[3] Zhang, M., Yang, Y., Liu, F., Jia, J., Xu, Q., Wang, L., Wang, Y., He, Y., Zhang, Y., Peng, Z., Wang, Q., Shen, H., Xu, Z., Zhang, Y., Yan, D., Zhang, H. and Ma, X. (2020) The Association of Husbands' Smoking with Wives' Dysglycemia Status: A Cross-Sectional Study among over 10 Million Chinese Women Aged 20 - 49. Journal of Diabetes, 12, 354-364. https://doi.org/10.1111/1753-0407.13009

[4] Satyanarayana, V.A., Jackson, C., Siddiqi, K., Chandra, P.S., Huque, R., Dherani, M., Nasreen, S., Murthy, P. and Rahman, A. (2021) A Behavior Change Intervention to Reduce Home Exposure to Second Hand Smoke during Pregnancy in India and Bangladesh: A Theory and Evidence-Based Approach to Development. Pilot \& Feasibility Studies, 7, Article No. 74. https://doi.org/10.1186/s40814-021-00811-5

[5] Kashaija, D.K., Mselle, L.T. and Mkoka, D.A. (2020) Husbands' Experience and Perception of Supporting Their Wives during Childbirth in Tanzania. BMC Pregnancy \& Childbirth, 20, Article No. 85. https://doi.org/10.1186/s12884-019-2715-7

[6] Karimiankakolaki, Z., Mazloomy Mahmoodabad, S.S., Kazemi, A. and Fallahzadeh, H. (2019) Designing an Educational Intervention on Second-Hand Smoke in Smoker Men on the Exposure of Pregnant Wives: A Protocol for a Randomized Controlled Trial. Reproductive Health, 16, Article No. 11. https://doi.org/10.1186/s12978-019-0673-1

[7] Sahebi, Z., Kazemi, A. and Loripoor Parizi, M. (2017) The Relationship between Husbands' Health Belief and Environment Tobacco Smoke Exposure among Their Pregnant Wife. Journal of Maternal-Fetal \& Neonatal Medicine, 30, 830-833. 
https://doi.org/10.1080/14767058.2016.1188071

[8] Ayuningtyas, D., Tuinman, M., Prabandari, Y.S. and Hagedoorn, M. (2020) Smoking-Related Social Control in Indonesian Single-Smoker Couples. International Journal of Behavioral Medicine, 1-11. https://doi.org/10.1007/s12529-020-09935-Z

[9] Zvolensky, M.J., Rogers, A.H., Manning, K., Hogan, J.B.D., Paulus, D.J., Buckner, J. D., Mayorga, N.A., Hallford, G. and Schmidt, N.B. (2018) Anxiety Sensitivity and Cannabis Use Problems, Perceived Barriers for Quitting, and Fear of Quitting. Psychiatry Research, 263, 115-120. https://doi.org/10.1016/j.psychres.2018.03.006

[10] Fernando, H.N., Wimaladasa, I.T.P., Sathkoralage, A.N., Ariyadasa, A.N., Udeni, C., Galgamuwa, L.S., Herath, P. and Kumarasinghe, N. (2019) Socioeconomic Factors Associated with Tobacco Smoking among Adult Males in Sri Lanka. BMC Public Health, 19, Article No. 778. https://doi.org/10.1186/s12889-019-7147-9

[11] Sahebi, Z., Kazemi, A., Loripour, M. and Shams, N. (2019) An Educational Intervention to Men for Reducing Environmental Tobacco Smoke Exposure in Their Pregnant Wives. Journal of Maternal-Fetal \& Neonatal Medicine, 32, 1595-1601. https://doi.org/10.1080/14767058.2017.1410792

[12] Dherani, M., Zehra, S.N., Jackson, C., Satyanaryana, V., Huque, R., Chandra, P., Rahman, A. and Siddiqi, K. (2017) Behaviour Change Interventions to Reduce SecondHand Smoking Exposure at Home in Pregnant Women-A Systematic Review and Intervention Appraisal. BMC Pregnancy \& Childbirth, 17, Article No. 378. https://doi.org/10.1186/s12884-017-1562-7

[13] Li, J., Wu, Q., Wu, X.-K., Zhou, Z.-M., Fu, P., Chen, X.-H., Yan, Y., Wang, X., Yang, Z.-W., Li, W.-L., Stener-Victorin, E., Legro, R.S., Ng, E.H.-Y., Zhang, H.P., Mol, B.W.J., Wang, C.C., Li, J., Wu, Q., Wu, X.-K. and Zhou, Z.-M. (2018) Effect of Exposure to Second-Hand Smoke from Husbands on Biochemical Hyperandrogenism, Metabolic Syndrome and Conception Rates in Women with Polycystic Ovary Syndrome Undergoing Ovulation Induction. Human Reproduction, 33, 617-625. https://doi.org/10.1093/humrep/dey027

[14] Satyanarayana, V.A., Jackson, C., Siddiqi, K., Chandra, P.S., Huque, R., Dherani, M., Nasreen, S., Murthy, P. and Rahman, A. (2021) A Behaviour Change Intervention to Reduce Home Exposure to Second Hand Smoke during Pregnancy in India and Bangladesh: A Theory and Evidence-Based Approach to Development. Pilot \& Feasibility Studies, 7, Article No. 74. https://doi.org/10.1186/s40814-021-00811-5

[15] Balázs, P., Grenczer, A., Rákóczi, I. and Foley, K.L. (2018) Continued Smoking Versus Spontaneous Quitting among Pregnant Women Living in a High Risk Environment. Central European Journal of Public Health, 26, 164-170.

https://doi.org/10.21101/cejph.a5048

[16] Prakash, S., Yadav, K., Bhardwaj, B. and Chaudhary, S. (2015) Incidence of Anemia and Its Socio-Demographic Determinants among Pregnant Women Attending for Antenatal Care: A Cross Sectional Study. International Journal of Medical and Health Research, 1, 12-17.

[17] Rahman, M.A., Rahman, M.S., Aziz Rahman, M., Szymlek-Gay, E.A., Uddin, R. and Islam, S.M.S. (2021) Prevalence of and Factors Associated with Anaemia in Women of Reproductive Age in Bangladesh, Maldives and Nepal: Evidence from Nationally-Representative Survey Data. PLoS ONE, 16, e0245335. https://doi.org/10.1371/journal.pone.0245335

[18] Van Manen, M. (1990) Researching lived experience:Human Science for an Action Sensitive Pedagory. State University of New York Press, New York.

[19] Lincoln, Y.S. and Guba, E.G. (1985) Naturalistic Inquiry. Sage, Beverly Hills, CA. 